Original Article

\title{
PRESCRIPTION ANALYSIS AND PREVALENCE OF POTENTIALLY INAPPROPRIATE MEDICATION USE IN OLDER ADULTS; AN OBSERVATIONAL STUDY
}

\author{
N. SENTHIL KUMAR, GEENA K. REJI, REEMA K. A., VIJAYARANGAN S., RAMYA A.
}

JKKMMRF'S Annai JKK Sampoorani Ammal College of Pharmacy, Ethirmedu, B. Komarapalayam 638183, Namakkal Dt, TamilNadu, The Tamilnadu DR. M. G. R. Medical University, Chennai Email: geenakadakketh@gmail.com

Received: 30 Oct 2019, Revised and Accepted: 25 Dec 2019

\section{ABSTRACT}

Objective: The objectives of the present study were to determine the prevalence of Potentially Inappropriate Medications and Adverse Drug Reactions in older adults and to collect doctors' responses regarding the PIM list or any other criteria to treat older adults in India.

Methods: This was an observational study conducted in different tertiary care hospitals of two districts, Erode and Salem after obtaining approval of the Institutional Ethics Committee. A sample of 250 older adults ( 60 y and above) and 97 doctors were included during the study period of 6 mo from February 2019 to July 2019. Inappropriate medications were identified by using 2019 updated Beer's criteria. The causality of the adverse events was assessed by Naranjo Adverse Drug Reaction Probability Scale.

Results: Out of the 250 prescriptions, only $86(34.4 \%)$ of the prescriptions were appropriate and $164(65.6 \%)$ were inappropriate. The most commonly inappropriate prescribed medications were diuretics, ranitidine, and tramadol. A total of 74 ADRs was observed in 74 patients. Of these, 57(22.8\%) ADRs were due to inappropriate medications listed in Beers criteria. There was a significant association between the occurrence of ADRs and the use of PIMs listed in 2019 updated Beer's criteria $[\chi 2=6.08, \mathrm{P}=0.013(\mathrm{df}=1)]$.

Conclusion: The study shows that there is a high prevalence of inappropriate medications and adverse drug reactions in hospitalized older adults. Beer's criteria can be used as a guideline by the physicians while prescribing the drugs to the geriatric population.

Keywords: Elderly patients, Older adults, Potentially inappropriate medications, Adverse Drug reactions, Beer's criteria

(C) 2020 The Authors. Published by Innovare Academic Sciences Pvt Ltd. This is an open access article under the CC BY license (http://creativecommons.org/licenses/by/4.0/) DOI: http://dx.doi.org/10.22159/ijpps.2020v12i2.36209. Journal homepage: https://innovareacademics.in/journals/index.php/ijpps

\section{INTRODUCTION}

Most developed countries have accepted the chronological age of $65 \mathrm{y}$ as a definition of 'elderly' or 'older person' [1]. In January, 1999 the Government of India adopted 'National Policy on Older Persons' and this policy defines 'senior citizen' or 'elderly' as a person who is of age $60 \mathrm{y}$ or above. The population ageing, started in the last century with developing countries, is now encircling developing countries too due to various reasons including better health care systems. Nearly, there are 104 million aged persons (aged $60 \mathrm{y}$ or above) in India; 53 million females and 51 million males, consistent with the population census 2011. From 5.6\% in 1961, the proportion has increased to $8.6 \%$ in 2011 [2]. The medications in which risks outweigh benefits are defined as Potentially Inappropriate Medications (PIMs). Inappropriate prescribing in the elderly population is a major public health issue, given its direct linkage to substantial morbidity, mortality and wastage of health resources that result from adverse drug reactions [3]. Appropriateness in healthcare has been defined as "the outcomes of a process of decision making that maximizes net health gains within society's available resources". Appropriate prescribing also associated with a reduction of over-use, under-use and misuse of treatment [4].

Prescribing quality for elderly patients can be improved by reducing irrational and inappropriate prescribing, thereby resulting in better health care. Therefore, assessment tools for the appropriateness of elderly pharmacotherapy are the essential fundamentals in defining whether an improvement in prescribing is needed. Different screening tools prepared for the assessment of the appropriateness of prescription and some of them are being used for assessment of the appropriateness of prescription [3]. The Beer's criteria firstly published in 1991, to determine potentially inappropriate prescribing in elderly nursing home residents [5]. The 2019 American Geriatric Society (AGS) Beer's criteria update contributes to the critically important evidence base and discussion of medications to avoid in older adults and the need to improve medication use in older adults. It includes 30 individual criteria of medications or medication classes to be avoided in older adults and 16 criteria specific to more than 40 medications or medication classes that should be used with caution or avoided in certain diseases or conditions. The 2019 AGS Beer's criteria is the third such update by the AGS and the fifth update of the AGS Beer's criteria since their original release [6].

\section{MATERIALS AND METHODS}

Study design and ethical considerations

This was an observational Study conducted in the inpatient departments of different tertiary care hospitals of two districts, Erode and Salem after obtaining approval of the Institutional Ethics Committee (REF NO: EC/PHARM D/2019-01).

\section{Sample size}

In this study 250 patients were enrolled, also 97 doctor's responses regarding the PIM list.

\section{Study duration}

This study was conducted for a period of 6 mo from February 2019 to July 2019.

\section{Data collection}

Patients who met the inclusion criteria were enrolled in the study. All information relevant to the study was collected from case records. The demographic characters, co-morbid conditions, drug dose, frequency, adverse drug reactions were documented in the pro forma. Responses from doctors are collected in a self-prepared questionnaire. Doctors of all departments were also included in the study.

\section{Inclusion Criteria}

Patients with $60 \mathrm{y}$ or above and all inpatients were included irrespective of their disease conditions, doctors of all departments were included. 


\section{Exclusion Criteria}

Patients below $60 \mathrm{y}$ and outpatients, doctors who were not willing to participate in the study and gynecology, pediatrics department were excluded.

\section{Data analysis and interpretations}

The study subjects were described in respect of their demographic profiles according to their age and gender. The continuous variables were described in terms of mean with standard deviation. The categorical variables were described in terms of percentages. In respect of categorical variables, the $\chi^{2}$ (Chi-square) test was taken into account. The P-values less than or equal to 0.05 (E0.05) w ere fixed as the level of significance.

\section{RESULTS}

A total of 250 hospitalized older adults was studied. The mean age of the study population was $71.6 \pm 7.0$ y (table 1 ). The study population comprised of males 144 (57.6\%) and females 106 (42.4\%) (fig. 1). A total of 690 diseases was diagnosed in 250 studied subjects, of which 73 (29.2\%) patients were diagnosed with three diseases/co- morbidities followed by $63(25.2 \%)$ with four or more, 58 (23.2\%) patients with two and $56(22.4 \%)$ with one disease/co-morbidities. The five most frequent diseases diagnosed were Hypertension 121 (17.53\%), followed by Diabetes Mellitus 120 (17.39\%), Coronary Artery Disease 26 (3.76\%), Chronic kidney disease 23 (3.33\%) and COPD 18 (2.60\%) (table 2).

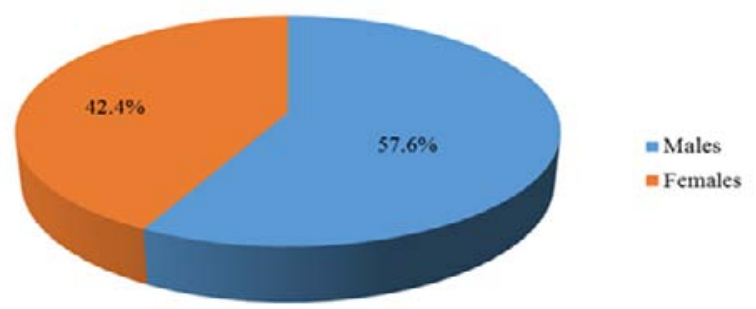

Fig. 1: Gender wise distribution

Table 1: Age-wise distribution

\begin{tabular}{llll}
\hline S. No. & Age group (years) & Frequency $(\mathbf{N}=250)$ & Percentage (\%) \\
\hline 1 & $60-69$ & 80 & 32.0 \\
2 & $70-79$ & 141 & 56.4 \\
3 & $80-89$ & 26 & 10.4 \\
4 & $\geq 90$ & 3 & 1.2 \\
Total & & 250 & 100.0 \\
\hline
\end{tabular}

Table 2: Most common diagnosis

\begin{tabular}{llll}
\hline S. No. & Diagnosis & Frequency & Percentage (\%) \\
\hline 1. & Hypertension & 121 & 17.53 \\
2. & Diabetes Mellitus & 120 & 17.39 \\
3. & Coronary Artery Disease & 26 & 3.76 \\
4. & Chronic Kidney Disease & 23 & 3.33 \\
5. & COPD & 18 & 2.60 \\
\hline
\end{tabular}

A total of 2500 drugs was prescribed in 250 prescriptions with a maximum of 5-9 drugs 109 (43.6\%), followed by 10-14 drugs 85 (34\%), 15-20 drugs 38 (15.2\%), 1-4 drugs 15 (6\%) and 20 or more drugs $3(1.2 \%)$. Out of the 2500 prescribed drugs, 297 (11.88\%) PIM drugs were identified (table 3). The most commonly identified PIM drug were Diuretics 48 (16.16\%) and Ranitidine 42 (14.14\%), followed by Tramadol 23 (7.74\%), Spironolactone 21 (7.07\%), Digoxin 17 (5.72\%), Glimepiride 16 (5.38\%), Diclofenac and Alprazolam 15 (5.05\%), Enoxaparin and Levetiracetam 12 (4.04\%), and the remaining drugs were occurred as single digits. Out of the 250 prescriptions, only $86(34.4 \%)$ of the prescriptions were appropriate and 164 (65.6\%) were inappropriate.

Table 3: Percentage distribution of PIM drugs

\begin{tabular}{lll}
\hline \multicolumn{2}{c}{ Potentially inappropriate } & medication (PIM) use according to 2019 updated Beer's Criteria \\
\hline Organ system, therapeutic category & Drugs & Instances, $\mathbf{N}=\mathbf{2 9 7}$ \\
\hline PIMS according to organ system and therapeutic category & \\
\hline Anticholinergics & Chlorpheniramine & $3(1.01)$ \\
& Promethazine & $2(0.67)$ \\
& Hydroxyzine & $1(0.33)$ \\
Anti-parkinsonian agents & Meclizine & $3(1.01)$ \\
Antispasmodic & Trihexyphenidyl & $1(0.33)$ \\
Anti-infective & Dicyclomine & $1(0.33)$ \\
Cardiovascular & Nitrofurantoin & $1(0.33)$ \\
Central alpha angonists & Prazosin & $6(2.02)$ \\
& Digoxin & $17(5.72)$ \\
& Nifedipine & $4(1.34)$ \\
Central Nervous System & Clonidine & $2(0.67)$ \\
Antipsychotics & Amiodarone & $6(2.02)$ \\
Benzodiazepines & Amitriptyline & $3(1.01)$ \\
& Phenobarbital & $1(0.33)$ \\
Nonbenzodiazepine, benzodiazepine receptor agonist & $6(2.02)$ \\
& Lorazepam & $15(5.05)$ \\
Endocrine & Zlprazolam & $6(2.02)$ \\
& Zolpidem & $1(0.33)$ \\
& Zaleplon & $1(0.33)$ \\
\end{tabular}




\begin{tabular}{lll}
\hline & Glimepiride & $16(5.38)$ \\
Pain medications & Glibenclamide & $5(1.68)$ \\
& Diclofenac & $15(5.05)$ \\
& Ibuprofen & $1(0.33)$ \\
& Ketorolac & $(2.02)$ \\
\hline Drugs to be used with caution in older adults & & $23(7.74)$ \\
& Tramadol & $1(0.33)$ \\
& Carbamazepine & $2(0.67)$ \\
\hline PIMS due to varying level of kidney function & Dabigatran & $48(16.16)$ \\
\hline Anti-infective & Diuretics & $1(0.33)$ \\
Cardiovascular or hemostasis & & $12(4.04)$ \\
Central nervous system & Ciprofloxacin & $21(7.07)$ \\
and analgesics & Enoxaparin & $4(1.34)$ \\
Gastrointestinal & Spironolactone & $12(4.04)$ \\
\hline
\end{tabular}

Out of 2500 drugs prescribed, 77 drugs (3.08\%) were causing ADR. The most common ADR drugs were observed under antidiabetic drugs $18(23.37 \%)$, followed by Cardiovascular drugs 14 (18.18\%), drugs acting on Central nervous system and analgesics 9 (11.68\%), Gastrointestinal drugs 8 (10.38\%), Antimicrobial drugs 5 (6.49\%), Anti-cancer drugs and others 4 (5.19\%),
Respiratory drugs 3 (3.89\%), Anti-hyperlipidemic drugs 2 (2.59\%) and Anti-tubercular drugs $1(1.29 \%)$. The most common organ system involved was Gastrointestinal 29 (39.18\%), followed by endocrine $14(18.91 \%)$, others $10(13.51 \%)$, cardiovascular 9 (12.16), Central nervous system $8(10.81 \%)$ and dermatology 4 (5.40\%) (table 4).

Table 4: Percentage distribution of ADR pattern among study subjects

\begin{tabular}{llll}
\hline S. No. & Organ system involved & Frequency & Percentage (\%) \\
\hline 1 & Gastrointestinal & 29 & 39.18 \\
2 & Endocrine & 14 & 18.91 \\
3 & Cardiovascular & 9 & 12.16 \\
4 & Central nervous system & 8 & 10.81 \\
5 & Dermatologic & 4 & 5.40 \\
6 & Others & 10 & 13.51 \\
\hline
\end{tabular}

A total of 74 ADRs was observed in 74 patients (29.6\%). Of these, 57 (22.8\%) ADRs were due to PIMs listed in Beers criteria and $17(6.8 \%)$ ADRs were due to other drugs. Of the $176(70.4 \%)$ patients not having any ADRs, 107 (42.8\%) patients were receiving PIMs and 69 (27.6\%) patients were not receiving any PIMs during their hospital stay (fig. 2).
There was a significant association between the occurrence of ADRs and the use of PIMs listed in 2019 updated Beer's criteria [ $\chi 2=6.08, \mathrm{P}$ $=0.013(\mathrm{df}=1)]$. The severity assessment of ADR was assessed using the Naranjo scale. Out of the 74 observed ADRs, $48.6 \%$ (36) were probable ADR and 54.1\% (38) was possible ADR.

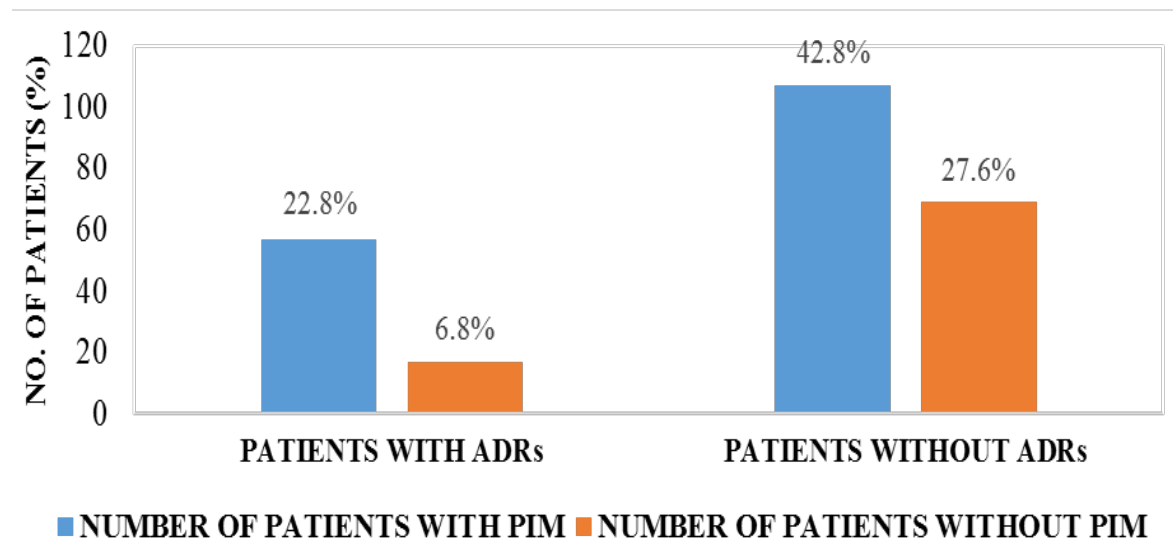

Fig. 2: ADRs and use of PIMs among study subjects

A total of 97 doctors' responses regarding PIM criteria or any other guidelines available in India to treat older adults were collected. Only 8.2\% (8) doctor's responded that they are aware of criteria to treat older adult in India and $91.8 \%$ (89) of the doctors were not aware of any such criteria. Only $6.2 \%$ (6) of the doctors informed that the PIM list or other guidelines were available and 93.8\% (91) replied as not available. $95.9 \%$ (93) of doctor's replied that there is a need of PIM criteria in India and $4.1 \%$ (4) replied that there is no need of such criteria. Among the doctors $98.9 \%$ (96) replied, the PIM will improve the clinical practice and only $1.1 \%$ (1) were replied negatively. Among the doctors $98.9 \%$ (96) had opined that the PIM list will reduce the chance of ADR and only $1.1 \%$ (1) opined negatively. The results were statistically very highly significant $(\mathrm{P}<0.001)$ (table 5). 
Table 5: PIM list can reduce the chance of ADR and improve the treatment option

\begin{tabular}{lllll}
\hline Response & Frequency & Percentage (\%) & X $^{2}$ & \\
\hline YES & 96 & 98.9 & 93.041 \\
NO & 1 & 1.1 & $\mathrm{df}=1$ \\
TOTAL & 97 & 100.0 & \\
\hline
\end{tabular}

\section{DISCUSSION}

The fastest-growing population in the 21st century is the people over $85 \mathrm{y}$ of age depicting aging of the population [7]. The aging population is accompanied by the increasing presence of diseases and so there is increased drug utilization by the older population. The elderly population is also vulnerable to adverse drug events which often can be prevented by detecting risk factors.

Many primary care physicians possess a poor knowledge of potentially inappropriate medications and are unaware of prescribing guidelines and screening tools for PIM use such as Beers Criteria [8].

The current study included a total of 250 older patients (aged $60 \mathrm{y}$ and above), of which the age group distribution between $70-79 \mathrm{y}$ is constituted with 141 (56.4\%), which is the highest percentage, whereas the study conducted by Senthilvel $\mathrm{R}$ et al. [9] reports that $84(42 \%)$ of the patients belong to the age group of $65-69 \mathrm{y}$. The male patients $(57.6 \%)$ were more prevalent than female patients. Similar gender prevalence was found in studies carried out in older inpatients by Rohit SR et al. [10] (59.8\%), Harugeri A et al. [11] (60.6\%). While some studies by Jhaveri et al. [12] (52.12\%), Shah et al. [13] (59.32\%) showed a higher prevalence of female patients.

In this study, most of the patients were diagnosed to have three diseases/co-morbidities 73 (29.2\%), while a prospective study by Vishwas HN et al. [14] reported that most patients diagnosed to have two diseases (3.7\%). In this study, Hypertension (17.53\%), Diabetes Mellitus (17.39\%), Coronary Artery Disease (3.76\%), Chronic Kidney Disease $(3.33 \%)$ and COPD (2.60\%) were the diagnosis of the most common disease. Studies conducted in medicine wards by Harugeri $e t$ al. [11] also reported Hypertension (41.5\%), Diabetes (34\%) and COPD (18.5\%) as the most frequent diagnoses in the study population. Polypharmacy is one of the risk factor for PIM use and adverse drug events. The present study shows that $43.6 \%$ patients were prescribed with 5 to 9 drugs. While a study conducted by Rohit SR et al. [10] reported $54.4 \%$ patients were prescribed with 10 or more drugs.

The prevalence of PIM use among hospitalized older adults in the present study was found to be $65.6 \%$, which is higher than that reported by Rohit SR et al. [10] (32.14\%), Harugeri et al. [11] (23.5\%) and Shah et al. [13] (29.3\%). The commonly used PIMs were diuretics $(16.16 \%)$ and ranitidine $(14.14 \%)$. While studies conducted by Rohit SR et al. [10] reported the most commonly used PIMs as clonidine $(19.6 \%)$, benzodiazepines $(15.8 \%)$, insulin sliding scale $(15.7 \%)$ and prazosin $(9.8 \%)$. In our study, only $34.4 \%$ of the prescriptions were appropriate and $65.6 \%$ were inappropriate, whereas in a study conducted by Senthilvel et al. [9], 64.5\% prescriptions were appropriate and $35.5 \%$ were inappropriate.

In this study, the majority of the ADRs were caused by anti-diabetic drugs (23.37\%) whereas in a study conducted by Jayanthi et al. [15] reports that the majority of ADRs were caused by Antimicrobials (22.5\%). A total of 74 ADRs in 74(29.6\%) patients were observed in the present study, which was higher than reported by Rohit SR et al. [10] (26.7\%). While a higher prevalence of ADRs was reported by Harugeri et al. [11] (35.9\%) among elderly patients. The most common organ system involved was gastrointestinal 29 (39.18\%), whereas in a study conducted by Jayanthi et al. [15] reported dermatological side effects $34.83 \%$ as the most common organ system affected.

The 57(22.8\%) ADRs were due to medications listed in Beer's criteria due to PIM use. There was a significant association between the occurrence of ADRs and the use of PIMs listed in 2019 updated Beer's criteria $[\chi 2=6.08, P=0.013(\mathrm{df}=1)]$. While in study conducted by Rohit SR et al.[10] and Harugeri et al. [11] reported that the medications other than listed in Beer's criteria were more likely to be associated with ADRs.

Among 97 doctors, most of them responded that there are no specific criteria in India to treat older adults and there is a need of PIM criteria in India in order to improve the quality of life in older adults.

\section{CONCLUSION}

The current study could assess the prescribing patterns of medicines in the geriatrics according to Beer's criteria 2019. The study report shows that the prevalence of PIM is increasing and PIM drugs are causing ADRs. The inappropriate medication use can be avoided by using Beer's criteria 2019. Most of the doctors said that there are no PIM list or any other guidelines available to treat older adults in India and opined that introducing PIM list can improve the quality of life of older adults. Beer's criteria can be used as a guideline by the physicians while prescribing the drugs to the geriatric population.

\section{LIMITATIONS}

- We planned to check the self-medication practices among the older adults, but the patients were incorporative for that and didn't get any responses.

- We planned to take responses from 120 doctors, but it gets limited to 97; the major problem with the doctors was they were so busy with their works and some of them were incorporative.

\section{ACKNOWLEDGMENT}

We heartily thank Dr. N. Senthil Kumar (Principal) and Ms. Ramya. A (Assistant Professor, Department of Pharmacy Practice), Annai JKK Sampoorani Ammal College of Pharmacy, Komarapalayam for providing their immense support throughout our study.

\section{FUNDING}

Nil

\section{AUTHORS CONTRIBUTIONS}

All authors have contributed equally in this piece of work.

\section{CONFLICT OF INTERESTS}

The authors have no conflict of interest to disclose.

\section{REFERENCES}

1. King M, Lipsky MS. Clinical implications of aging. Disease Month 2015;61:467-74.

2. Government of India, Ministry of Statistics and programme implementation. Elderly in India-Profiles and Programmes. New Delhi: Central statistics Office; 2016. p. 1-18.

3. Kashyap M, Iqbal MZ. A review of screening tools used for the assessment of the appropriateness of prescription`s among elderly patients. J Pharm Biosci 2014;3:72-9.

4. Aronson JK. Rational prescribing, appropriate prescribing. $\mathrm{Br} \mathrm{J}$ Clin Pharmacol 2004;57:229-30.

5. Beers MH, Ouslander JG, Rollingher I, Reuben DB, Brooks J, Beck JC. Explicit criteria for determining inappropriate medication use in nursing home residents. Arch Intern Med 1991;15:1825-32.

6. By the 2019 American Geriatrics Society Beers Criteria ${ }^{\circledR}$ Update Expert Panel. American Geriatrics Society 2019 updated ags beers criteria ${ }^{\circledR}$ for potentially inappropriate medication use in older adults. J Am Geriatric Soc 2019:67:674-94.

7. Anderson GF, Hussey PS. Population aging: a comparison among industrialized countries. Health Aff (Millwood) 2000;19:191-203. 
8. Ramaswamy R, Maio V, Diamond JJ, Talati AR, Hartmann CW, Arenson C, et al. potentially inappropriate prescribing in elderly: Assessing doctor knowledge, confidence and barriers. J Eval Clin Pract 2011;17:1153-9.

9. Senthilvel N, Sowmya R, Sreerekha S, Srisha R. A study on prescribing pattern of drugs in geriatrics using Beer's criteria at a private corporate hospital. Int J Pharm Sci Res 2015;6:4810-25.

10. Rohit SR. Evaluation of potentially inappropriate medication use and risk of adverse drug reactions in hospitalized older adults: an observational study in a tertiary care hospital. Indian J Pharm Practice 2018;11:79-85.

11. Harugeri A, Joseph J, Parthasarathi G, Ramesh M, Guido S. Potentially inappropriate medication use in elderly patients: a study of prevalence and predictors in two teaching hospitals. J Postgrad Med 2010;56:186-91.

12. Jhaveri BN, Patel TK, Barvaliya MJ, Tripathi C. Utilization of potentially inappropriate medications in elderly patients in a tertiary care teaching hospital in India. Perspect Clin Res 2014;5:184-9.
13. Shah KN, Joshi HM, Christian RP, Patel KP, Malhotra SD. Prevalence of potentially inappropriate medications and prescription cost analysis among older cardiac patients in an outpatient department of a tertiary care hospital in India. J Basic Clin Pharm 2016;7:110-5.

14. Vishwas HN, Harugeri A, Parthasarathi G, Ramesh M. Potentially inappropriate medication use in Indian elderly: comparison of beer's criteria and screening tool for older persons potentially inappropriate prescriptions. Geriatric Gerontol Int 2012;12:506-14

15. Jayanthi CR, Renuka M, Panchaksharimath P. An observational study to analyse the adverse drug reactions among the elderly at a teritary care hospital. Biomed Pharmacol J 2017;10:345-52.

16. Borah L, Devi D, DEbnath PK, Deka D. A study of drug utilization pattern of the geriatric patients in the department of geriatric medicine in a tertiary care hospital in Assam, India. Asian J Pharm Clin Res 2017;10:122-6.

17. Anju SM, Jacob C, Benchamin A, Rodrigues PA. A prospective study on geriatric prescribing pattern and medication adherence in a tertiary care hospital. Asian J Pharm Clin Res 2017;10:220-5. 